\title{
Global-warming sceptics left out in the cold
}

Washington

A widely noted discrepancy between satellite-based and ground-based measurements of average global temperature does not call into question the fact that the Earth's atmosphere is warming up, according to a US National Research Council (NRC) panel.

The panel includes researchers who in the past have argued that the lack of evidence for warming from data gathered by satellitebased equipment cast doubt on global warming. Its unanimous conclusion therefore seems to refute one of the main arguments of opponents to the introduction in the United States of compulsory measures.

But positions on the global-warming issue are now so deeply entrenched that the finding is unlikely to move many policymakers, according to congressional and administration staff on both sides of the debate. The Clinton administration has no plans to submit the Kyoto Protocol on greenhouse-gas emissions to the US Senate, and the Congress continues to oppose most actions or incentives aimed at reducing such emissions.

The NRC panel concluded that an increase in global mean surface temperature over the past 20 years "is undoubtedly real and is substantially greater than the average rate of warming during the twentieth century". Satellite data showing a lack of warming of the upper atmosphere were reliable, it said, but it rejected the contention that this called ground-based data into question. "We're saying emphatically that it is not valid to equate the two sets of measurements," explains John Wallace, chair of the panel and a climatologist at the University of Washington in Seattle.

The report states that the 20-year period monitored by satellite-mounted microwave sounding units was too short to indicate long-term climate behaviour. Wallace says that if earlier tropospheric temperature data from balloons are taken into account, and the record is examined over 30 or 40 years, the discrepancy between the surface and the troposphere disappears.

When the satellite-based data first appeared almost a decade ago, sceptics jumped on it as evidence that fears of global warming were overblown. "People started talking about the satellite data as a surrogate for the surface record," says Wallace. "There remains some residual misunderstanding that the two ought to be the same."

Wallace says that the disparity between the records may be due to short-term perturbations in the climate record - possibly caused by volcanic activity - or may point to limitations in existing climate models, which assume a close coupling between mean temperatures at the surface and those in the upper atmosphere.

Sceptics of climate change have moved on from their earlier contention that the satellite data discredit the ground data to argue instead that the discrepancy between the two discredits the best available climate models. "What this tells me", says one republican congressional official who is sceptical about climate change and who was briefed on the report's contents last week, "is that the models need a lot of work."

John Christy, a panel member and atmospheric scientist at the University of Alabama at Huntsville, who specializes in analysing satellite-generated data, says the models "require improvement", but adds that "it is not right to say that they are useless".

Indeed, few observers of the climatechange debate in Washington expect that the NRC's findings will have much immediate impact. "It's like a game of 'whack-a-mole", says a democrat official on the Science Committee at the House of Representatives. "Every time you pin something down, another 'unresolved issue' comes up."

But Robert Park, a professor of physics at the University of Maryland and spokesperson for the American Physical Society, says the controversy is helping to generate "great science". The report is "evidence that the scientific process is working", he says. Colin Macilwain

\section{Diversity convention in the balance}

\section{Washington}

International negotiators gather this week in Montreal to try and negotiate a biosafety protocol that would regulate the international movement of living organisms. After the dramatic failure of last November's meeting of the World Trade Organization (WTO) in Seattle, hopes for agreement may well be equally forlorn.

Parties to the Convention on Biological Diversity (CBD) will meet to bridge divisions over whether a biosafety protocol should cover agricultural commodities, and whether it should take precedence over the rules on international trade set by the WTO.

As has become routine in environmental negotiations, deep divisions between the European Union and the United States and its food-exporting allies, including Canada and Argentina, will dominate the meeting. Europe favours a powerful biosafety protocol, whereas the US group's priority is to protect agricultural trade. Developing countries will broadly support the European position, and a small number of nations known as the Compromise Group - will attempt to bridge the gap.

Only "a miracle" can produce an agreement, says Calestous Juma, former director of the $\mathrm{CBD}$ and now a professor at the Center for International Development at Harvard University. "The fundamental issue is between the European Union and North America: the rest of the world is coming along to watch."

Two main issues divide Europe and the United States, negotiators say. One is the application of the biosafety protocol to commodity crops: the European Union and developing countries want it to govern crop movement, while the United States wants an agreement covering only living organisms.

The second, more vexing question is

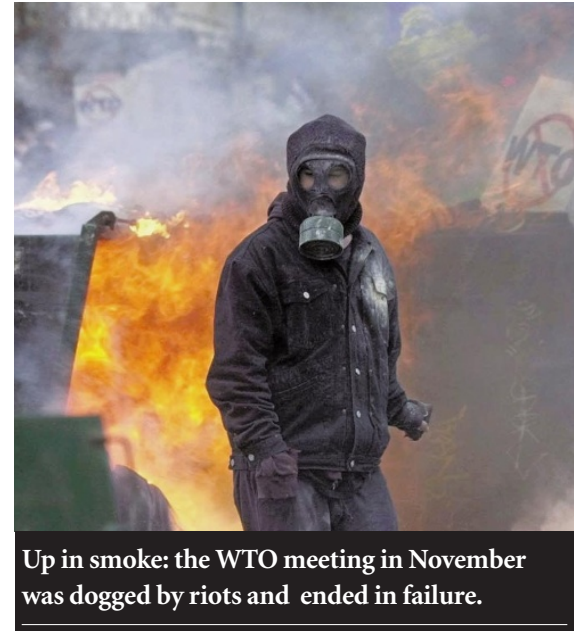

whether the protocol should contain a 'savings clause', which would concede its subserviance to WTO rules. "The European Union wants this to overrule the trading rules," says one European diplomat in Washington. "The United States will never agree to that."

Failure to break this impasse in Montreal - on top of two rounds of largely fruitless meetings since the parties failed to resolve the issue last February in Cartegena, Colombia - could spell trouble for the $\mathrm{CBD}$, one of three international mechanisms established to protect the global environment at the 1992 Rio Earth Summit.

Juma says that failure to negotiate a biosafety protocol will damage the credibility of the convention as a means of tackling more complex issues, such as the sharing of genetic resources.

But a senior US government official says recent discussions have been "less ideological and more constructive" than at Cartagena, adding: "We come to Montreal prepared to negotiate in good faith." Colin Macilwain 